\title{
The synthesis of copper complex with 1D chain
} Liyan You ${ }^{1, a}$, Hui Jiang ${ }^{1, b}$ and Chaohong Ma ${ }^{1, c}$

\author{
${ }^{1}$ School of Arts and Science, Jilin Agricultural Science and Technology University, Jilin 132101, \\ China
}

ayly5466@163.com, b6983318@qq.com, c573329347@qq.com

Keywords: 2-Methyl-1,4-benzenedicarboxylic acid; copper complex; crystal structure; Thermal Stability Behavior

Abstract: $\quad$ The $\quad$ complex $\quad\left\{\left[\mathrm{Cu}\left(\mathrm{C}_{9} \mathrm{H}_{8} \mathrm{O}_{4}\right)(\mathrm{DMSO})_{2}(\mathrm{H} 2 \mathrm{O})_{2}\right] \cdot(\mathrm{DMSO})_{2}\right\} \mathrm{n}$ $\left(\mathrm{C}_{9} \mathrm{H}_{8} \mathrm{O}_{4}=2-\right.$ Methyl-1,4-benzenedicarboxylic acid, DMSO = dimethyl sulfoxide) was synthesized by reaction of $\mathrm{Cu}\left(\mathrm{NO}_{3}\right)_{2} \cdot 3 \mathrm{H}_{2} \mathrm{O}$. The crystal structure of the copper(II) complex has been determined and studied by X-ray diffraction. The complex is monoclinic, space group $P 2(1) / c$, with $a=10.196$ (3) $\AA, \quad b=11.364(2) \quad \AA, \quad c=16.921 \quad$ (4) $\AA, \quad \alpha=90.1, \quad \beta=101.54$, $\gamma=89.6^{\circ}, V=1960.59(6) \AA^{3}, Z=4$. The copper complex is $1 \mathrm{D}$ hydrophobic chain structure, because of the hydrophobic properties of the $-\mathrm{CH}_{3}$.

\section{Introduction}

The synthesis, structure and properties of coordination polymers are the focus of current chemical research ${ }^{[1-4]}$. Aromatic carboxylic acids and metal ions form a variety of structurally diverse complexes. The literatures have reported complexes, which are constructed terephthalic acid and copper (II), with binuclear copper structural unit is the most common, the oxygen atom of carboxyl group in the cis form and distribution along the central ion double teeth, the formation of paddle wheel structure of the four carboxyl bridged bimetallic complexes for nuclear, general two-dimensional layered structure.

Copper is a necessary trace element for the human body. Copper plays an important role in transmitting electrons, transporting oxygen and eliminating superoxide anion in the course of life. Complexes of aromatic carboxylic acids with metal ions have rich structure and special properties, and show potential applications in many fields such as materials, drugs and so on. The aromatic carboxylic acid ligands have certain rigidity and stability in structure. The introduction of different substituents on the aromatic ring has different effects on the structure and properties of the complexes $^{[5]}$. The dimethyl sulfoxide can form stable complexes with a variety of metal ions. In addition, the aromatic carboxylic acid ring has potential accumulation of aromatic rings, so it is easy to build all kinds of functional supramolecular systems ${ }^{[6-8]}$. Therefore, dimethylene sulfoxide is widely used in the molecular design of Solid Complexes. In this paper, we have successfully constructed 2D supramolecular complex, using the ligand dimethyl sulfoxide (DMSO) reacts with 2-Methyl-1,4-benzenedicarboxylic acid and cupric nitrate, which are connected through $\pi-\pi$ stacking and hydrogen bond interactions.

\section{Materials and physical measurements}

All solvents and chemicals purchased from commercial sources were of reagent grade and used without further purification. IR spectra were performed on a Shimizu spectrum FT-IR spectrometer with $\mathrm{KBr}$ pallets in the range of $4000 \sim 400 \mathrm{~cm}^{-1}$. The elemental analyses for $\mathrm{C}, \mathrm{H}$, $\mathrm{N}$ and $\mathrm{S}$ were carried out on a Leeman elemental analyzer. The crystal data were collected on a Rigaku Xtalab area detector diffractometer at room temperature.

\section{Synthesis of complex}

Take cupric nitrate (1mmol, 0.1876g) to dissolve in water $(10 \mathrm{~mL})$. Then 
2-Methyl-1,4-benzenedicarboxylic acid (1mmol, $0.1816 \mathrm{~g})$ is dissolved in $10 \mathrm{~mL}$ $\mathrm{N}, \mathrm{N}-$ Dimethylformamide. Mix the 3 solutions together. The reaction is stirring for about $2 \mathrm{~h}$ at normal temperature. The resulting solution was kept at room temperature by slow evaporation for about several days, yielding light blue rectangle single crystals. Yield: $42.5 \%$.Selected IR data $\left(\mathrm{cm}^{-1}\right)$ : (-COOH) $1683.3 \mathrm{~cm}^{-1}, 1288 \mathrm{~cm}^{-1}, 942 \mathrm{~cm}^{-1}, \quad(\mathrm{~S}=\mathrm{O}) 1256.5 \mathrm{~cm}^{-1}$ and $1131.1 \mathrm{~cm}^{-1}, 998.2 \mathrm{~cm}^{-1}$ and $\left(-\mathrm{CH}_{3}\right) 2882.3 \mathrm{~cm}^{-1}, 1438.7 \mathrm{~cm}^{-1}$. Anal. Calcd. (\%) for C17H36 O10 S4 Cu: C 34. $58 \%, \mathrm{H} 5$. $76 \%$, S 21. 69\%;9.46. Found (\%):C 34. 81\%, H 5. 23\%, S 21. 37\%

\section{Structure determination}

A suitable single crystal of complex $(0.15 \mathrm{~mm} \times 0.26 \mathrm{~mm} \times 0.14 \mathrm{~mm})$ was selected and glued on the tip of a glass fiber. The crystal structure was determined at $298 \mathrm{~K}$ on an X-ray diffractometer, a Rigaku Xtalab detector diffractometer by using a $\mathrm{Cu} K \alpha$ radiation $(\lambda=0.154 \AA)$. All structures were solved using direct methods with SHELXS and refined by full-matrix leastsquares on $F^{2}$ using the SHELXL14 software within OLEX2. All the non-hydrogen atoms were refined anisotropically with displacement parameters. The hydrogen atoms were generated geometrically and treated by a mixture of independent and constrained refinement using a riding model. Crystal data and structure parameters for the title complex are listed in Table 1.

Table 1 Crystal data for Copper(II) Compound

\begin{tabular}{ll}
\hline Polymers & Complex \\
\hline Formula & C17H36 O10 S4 Cu \\
Formula weight & 590.13 \\
Temperature(K) & $223(2)$ \\
Wavelength(A) & 0.154 \\
Crystal sizes $(\mathrm{mm})$ & $0.12 \mathrm{~mm} \times 0.34 \mathrm{~mm} \times 0.15 \mathrm{~mm}$ \\
Color & light blue \\
Crystal system & monoclinic \\
Spaces group & $\mathrm{P} 2(1) / \mathrm{c}$ \\
$\mathrm{a}(\AA)$ & $10.196(3)$ \\
$\mathrm{b}(\AA)$ & $11.364(2)$ \\
$\mathrm{c}(\AA)$ & $16.921(4)$ \\
$\alpha\left(\left(^{\circ}\right)\right.$ & 90.1 \\
$\beta\left(^{\circ}\right)$ & 101.54 \\
$\gamma\left({ }^{\circ}\right)$ & 89.6 \\
$V\left(\AA^{3}\right)$, & $1960.59(6)$ \\
$Z$ & 4 \\
\hline
\end{tabular}


Table 2 elected Bonds Lengths (nm) and Bonds Angles( ${ }^{\circ}$ )

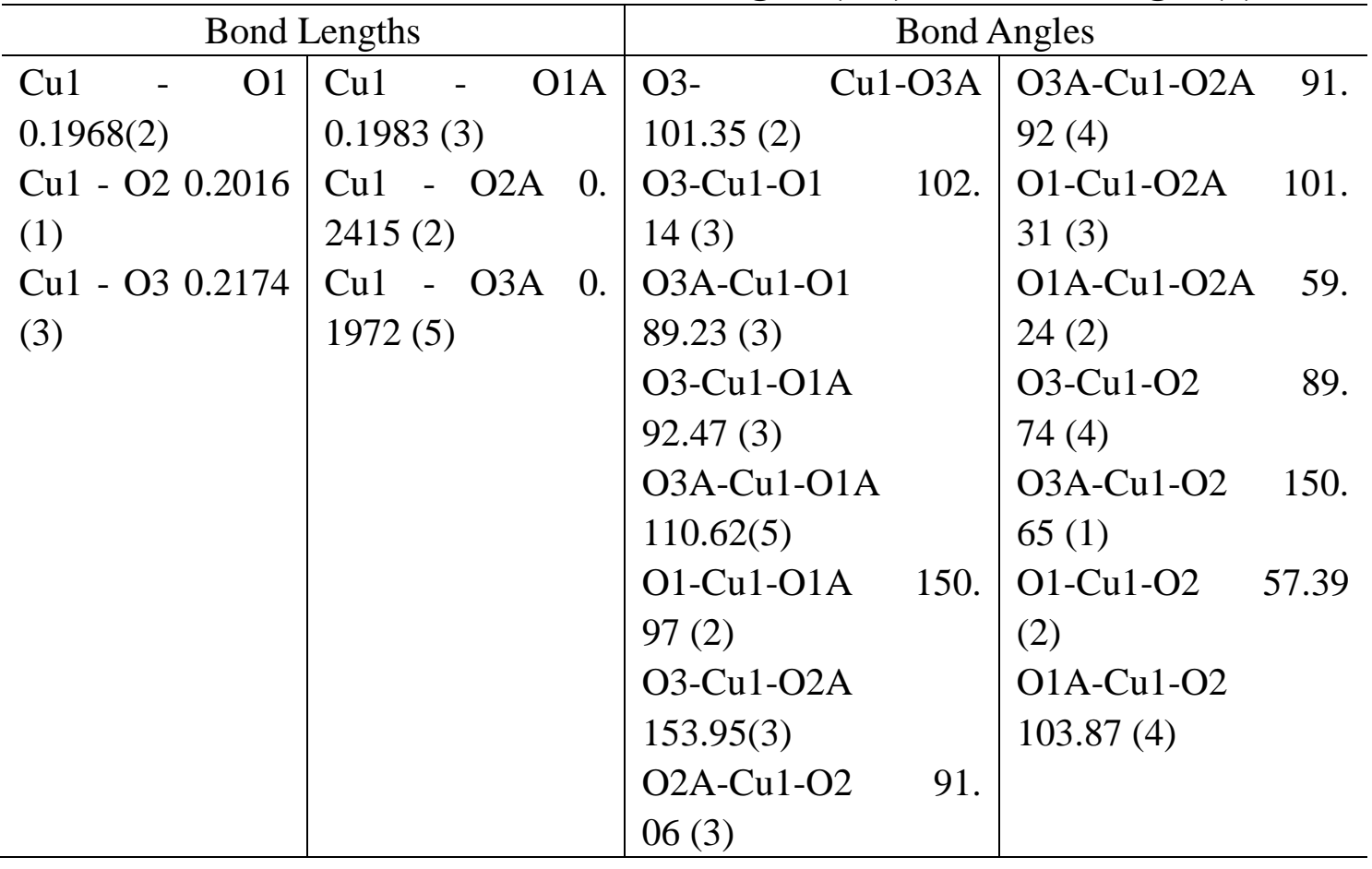

Symmetry transformations used to generate equivalent atoms: $-x+1, y,-z+1$;

\section{Results and Discussion}

\section{Structural Description}

As shown in Fig1., the titled complex is composed of copper(II), 2-Methyl-1,4-benzenedicarboxylic acid, and DMSO molecules. Cul coordinated with six atoms. And there are four oxygen atoms coordinated with $\mathrm{Cu} 1$ atoms in the form of chelate, which comes from two carboxyl groups.The four oxygen atoms are occupying four sites of $\mathrm{Cu}$ atoms. The other two coordinated oxygen atoms are provided by the DMSO molecule. The bond length of the Cu1 - O1 is 0.1968 (2) nm. The bond length of $\mathrm{Cu} 1$ - O1A is 0.1983 (3). The bond length of $\mathrm{Cu} 1$ - O2 is 0.2016 (1). The bond length of $\mathrm{Cu} 1-\mathrm{O} 2 \mathrm{~A}$ is $0.2415(2)$. The bond length of $\mathrm{Cu} 1-\mathrm{O} 3$ is 0.2174 (3). The bond length of Cu1-O3A is 0.1972 (5). The bond length and bond angle data provided by Table 2 show that the atom $\mathrm{Cu} 1$ is in the coordinate center of the deformed eight faces.

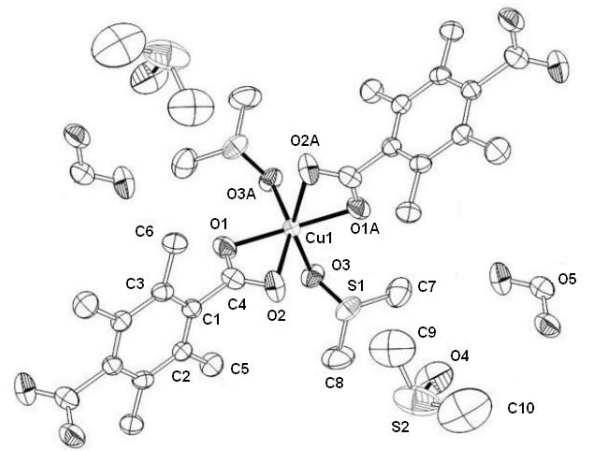

Fig.1 Crystal Structure of complex

In the structure of the title compound, the oxygen atom on the carboxyl group and the $\mathrm{Cu} 1$ atom are connected in a chelate form into a one-dimensional zigzag chain structure. The chain depends on the weak action of $\mathrm{C}-\mathrm{H} . . . \pi$ interacts with each other to form crystals.

\section{IR Analysis}

The infrared spectra of ligands and coordination polymers were determined by the potassium 
bromide tabletting method in the range of $4000-400 \mathrm{~cm}^{-1}$ wavenumbers. The infrared absorption peak of complex is $1683.3 \mathrm{~cm}^{-1} 1288 \mathrm{~cm}^{-1} 942 \mathrm{~cm}^{-1}$, which indicates the coupled vibration peak of terephthalic acid. The absorption peak at $1442 \mathrm{~cm}$ belongs to the benzene. We also find absorption peaks at $1256.5 \mathrm{~cm}^{-1}$ and $1131.1 \mathrm{~cm}^{-1}, 998.2 \mathrm{~cm}^{-1}$, which belong to $\mathrm{S}=\mathrm{O}$ of dimethyl sulfoxide (DMSO). The absorption peaks found around $2882.3 \mathrm{~cm}^{-1}$ and $1438.7 \mathrm{~cm}^{-1}$ belong to the characteristic absorption peaks of $-\mathrm{CH}_{3}$. We also have observed that $-\mathrm{OH}$ stretching frequency of water molecules coordinate because of the presence of the broad band around 3430 $\mathrm{cm}^{-1}$.Comparison with the infrared spectra of the ligand and the synthesized copper complex, it makes clear that the coordination bonds have formed.

\section{Thermal Stability Behavior}

In order to discuss the thermal stability of the Copper(II) complex, the thermogravimetric analysis of the copper complex is carried out under conditions of temperature with the increasing rate $10^{\circ} \mathrm{C} / \mathrm{min}$, from $25^{\circ} \mathrm{C}$ to $450^{\circ} \mathrm{C}$. In Fig2., there are three steps of the decomposing. Thermal analysis of complex shows that the weight loss starts at $17-122^{\circ} \mathrm{C}$, the total loss of $6.314 \%$ attributed to the release of $\mathrm{H}_{2} \mathrm{O}$, which is calculated $6.102 \%$. Then the weight loss starts at $122-351{ }^{\circ} \mathrm{C}$, the total loss of $26.102 \%$ attributed to the release of DMSO, which is calculated $26.494 \%$. The exquisite weight loss appears at $351-389^{\circ} \mathrm{C}$, which is attributing to the decomposing of 2-Methyl-1,4- benzenedicarboxylic acid.

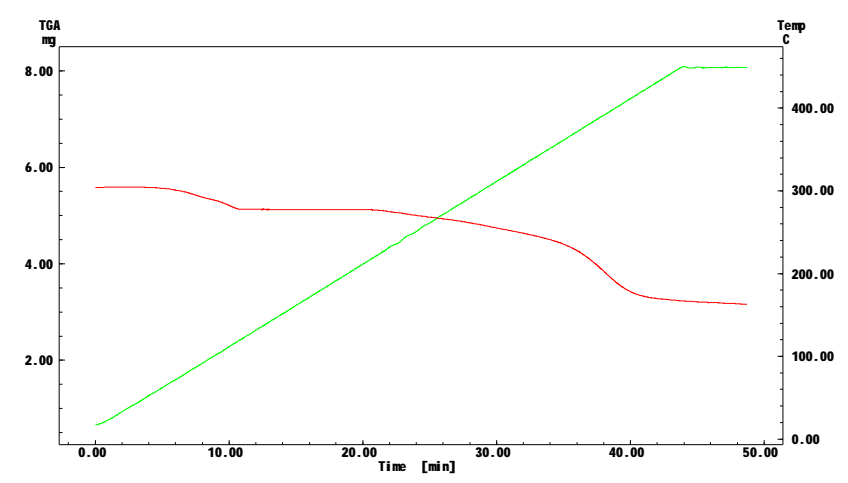

Fig.2 The thermogravimetric analysis of the copper complex

\section{Conclusions}

In this paper, we have presented the Copper(II) complex $\left\{\left[\mathrm{Cu}(\mathrm{C} 9 \mathrm{H} 8 \mathrm{O} 4)(\mathrm{DMSO}) 2(\mathrm{H} 2 \mathrm{O})_{2}\right] \cdot(\mathrm{DMSO})_{2}\right\} \mathrm{n} \quad\left(\mathrm{C}_{9} \mathrm{H}_{8} \mathrm{O}_{4}=2-\right.$ Methyl-1,4-benzenedicarboxylic acid, and DMSO=dimethyl sulfoxide). The crystal structure of the Copper (II) complex has been determined and studied by X-ray diffraction, which is also characterized by elemental analysis, IR spectra. Because of the large size of methyl, the carboxyl group and benzene ring is not in the coplanar. There is a certain angle of the carboxyl group and benzene ring. Therefore, the carboxyl and metal ions can not form paddle and wheel structures, but chelating in coordination. Finally, the title compound is $1 \mathrm{D}$ hydrophobic chain structure, because of the hydrophobic properties of the $-\mathrm{CH}_{3}$.

\section{Acknowledgements}

This work was supported by Foundation of Jilin Educational Committee ([2015]377); Science and Technology Development Funds of Jilin city (20156431); and Youth Foundation of Jilin Agricultural Science and Technology University ([2014]209). 


\section{References}

[1]Li, H-L, Eddaoudi, et al. EstablishingM icroporosity in Open Metal-Organic Frameworks: Gas Sorp tion Isotherm s for $\mathrm{Zn}$ (BDC) (BDC $=1,4$ - Benzenedicarboxylate) [J]. J. Am. Chem. Soc. , 1998, 120: 8571 - 8572.

[2]Wang, R-H, Hong, et al. Tris( 1-1, 4-benzenedicarboxylate) tetrakis ( dimethyl sulfoxide) di- $\mu 3$-hydroxo-tetrazinc dehydrate[J]. Acta Cryst, 2001, E (57): 277 - 279.

[3] Yaghi O M, Davis C E, Li G M, et al. Selective Guest B inding by Tailored Channels in a 3D Porous Zinc (II) - Benzenetricarboxylate Network[J]. J. Am. Chem. Soc., 1997, 119: 2861 - 2868.

[4]Li H, Eddaoudi M, O'Keeffe M, et al. Design and synthesis of an exceptionally stable and highly porous metal-organic framework[J]. Nature, 1999, 402: 276-279.

[5] EddaoudiM, Kim J, O'Keeffe M, et al. A Framework Deliberately Designed To Have the NbO Structure Type [J]. J. Am. Chem. Soc., 2002, 124: 376 - 377.

[6] EddaoudiM, Kim J, Rosi N, et al. Systematic Design of Pore Size and Functionality in Isoreticular MOFs and Their App lication in Methane Storage[J]. Science, 2002, 295: 469-472.

[7] Tao, J, Tong, et al. Blue photoluminescent zinc coordination polymers with supertetranuclear cores[J]. Chem. Commun. , 2000, 2043 - 2044.

[8]Vodak D T, B raun M E, Kim J, et al. Metal-organic frameworks constructed from pentagonal antip rismatic and cuboctahedral secondary building units[J]. Chem. Commun., 2001, 2534 - 2535.

[9] Edgar, M, M itchell, Solid - State Transformations of Zinc 1, 4 - Benzenedicarboxylates Mediated by Hydrogen-Bond-Form ing Molecules[J]. Chem. Eur. J., 2001, 5168 - 5175. 